\title{
El Tribunal Constitucional chileno y la reforma de 2005. Un enroque entre jueces de carrera y académicos ${ }^{*}$
}

\author{
Diego G. Pardow Lorenzo** \\ Sergio Verdugo Ramírez***
}

\begin{abstract}
RESUMEN
Después de la reforma constitucional de 2005, el Tribunal Constitucional chileno se está volviendo más activo en el ejercicio de sus poderes en contra del Poder Ejecutivo. Ello se explica principalmente debido al enroque que sufrió la composición del Tribunal Constitucional, donde un grupo de jueces provenientes del mundo académico reemplazaron a un grupo de jueces ligados a la carrera judicial. Los jueces chilenos tienen una larga reputación de ser deferentes con el gobierno y de dictar sentencias de manera unánime. Esta actitud, sin embargo, va más allá de la afiliación partidista. Como se muestra en este artículo, los cambios en el comportamiento del Tribunal parecen estar más vinculados a cambios en la cultura jurídica subyacente, que a diferencias en la orientación política de los ministros.
\end{abstract}

Tribunal Constitucional chileno - sentencias unánimes - disidencias judiciales

\section{The Chilean Constitutional Tribunal and the 2005 Amendment. A Castling Between Carrer and Academic Judges}

\section{ABSTRACT}

After a constitutional amendment in 2005, the Chilean Constitutional Tribunal is becoming more active in exercising its powers against the executive branch. This effect is mainly due to a castling in the composition of the court between career judges and justices coming from the academia. Chilean judges have had a long-standing reputation of being deferential with the government and of following a rule of unanimity. That attitude, however, goes beyond partisan affiliation. As it is shown in this paper, the changes in the behavior of the court seems to be more related with a change in the underlying legal culture, than with differences in the partisan affiliation of the justices.

Chilean Constitutional Tribunal - Unanimous Judicial Opinions - Dissenting Opinions

\footnotetext{
* Este trabajo contó con el apoyo del concurso de fondos de investigación de la Dirección de Investigación de la Universidad del Desarrollo. No de proyecto: 20111014171242965112.

** Abogado, Máster y Doctor en Derecho. Investigador del Programa de Gobierno, Derecho y Mercados, Universidad Diego Portales. Correo electrónico: dpardow@berkeley.edu

*** Abogado, Máster en Derecho, Profesor de Derecho Constitucional e investigador del Centro de Justicia Constitucional de la Facultad de Derecho de la Universidad del Desarrollo. Correo electrónico: sverdugor@udd.cl

Artículo recibido el 11 de agosto de 2014 y aceptado para su publicación el 27 de marzo de 2015.
} 


\section{INTRODUCCIÓN}

$\mathrm{L}$ a literatura acerca de la manera en que los jueces dictan sentencias (judicial decisionmaking) ha crecido exponencialmente en las últimas décadas. Por una parte, el realismo jurídico y su enfoque centrado en las preferencias individuales de los jueces ha encontrado un notable aliado en el modelo actitudinal (attitudinal model), donde el razonamiento judicial se explica a partir de la ideología política de los jueces ${ }^{1}$. Por otra parte, también ha existido un resurgimiento de las explicaciones basadas en el formalismo legalista, según estas el comportamiento judicial responde únicamente a lo que las reglas jurídicas disponen ${ }^{2}$.

Independientemente del mérito sustantivo de cada una de estas teorías, una evaluación apropiada requiere considerar qué es lo que los jueces hacen en la práctica. Ello, a su vez, exige no solo un registro sistemático de las votaciones individuales de los jueces, sino también de proxies confiables acerca de sus inclinaciones políticas.

Ambos aspectos son problemáticos, tanto en Chile como en la generalidad de los países de Europa continental ${ }^{3}$. Los votos disidentes tienden a ser escasos, existiendo países donde es obligatorio que las sentencias se dicten de manera unánime ${ }^{4}$. Por lo demás, es

${ }^{1}$ Por ejemplo, Schubert, G., The judicial Mind: The Attitudes and Ideologies of Supreme Court Justices, 1946-1963, Northwestern University Press, Chicago, 1965; Rohde, D. y Spaeth H., Supreme Court Decision Making, WH Freeman, San Francisco, 1976; Brenner, S. y Spaeth H., Stare Indecisis: The Alteration of Precedent on the Supreme Court 1946-1992, Cambridge University Press, New York, 1995; Epstein, L., Segal J. y Spaeth H., "The Norm of Consensus on the U.S. Supreme Court", en American Journal of Political Science, Vol. 45, $\mathrm{N}^{\mathrm{o}} 2,2001$, p. 362.

${ }^{2}$ Wald, P., “A Response to Tiller and Cross”, en Columbia Law Review, Columbia Law School, 1999, pp. 235-261; Edwards, H. y Livermore M., "Pitfalls of Empirical Studies That Attempt to Understand the Factors Affecting Appellate Decisionmaking”, en Duke Law Journal, Vol. 58, 2008, pp. 1895-1990; Batchis, W., "Constitutional Nihilism: Political Science and the Deconstruction of the Judiciary", en Rutgers Journal of Law E Public Policy, Vol. 6, 2008, pp. 1-35.

${ }^{3}$ En esta área de investigación, la mayoría del trabajo se centra en la Corte Suprema norteamericana. Esta Corte suele dictar sentencias divididas, entregándoles a los investigadores un número importante de votos disidentes. En seguida, sus jueces suelen ser nombrados mediante un proceso que permite recopilar antecedentes verificables acerca de sus inclinaciones políticas. Ambas circunstancias ayudan a construir un modelo centrado en la formación de coaliciones internas. Por ejemplo, Segal, J. y Cover A., "Ideological Values and the Votes of US Supreme Court Justices”, en American Political Science Review, Vol. 83, 1989, p. 557; Epstein, L., Landes W., y Posner R., "Why (and When) Judges Dissent: A Theoretical and Empirical Analysis”, en Journal of Legal Analysis, Vol. 3, No 1, 2011, pp. 101-137; Martin, A., Quinn, K. y Epstein L., "The Median Justice on the U.S. Supreme Court", en North Carolina Law Review, Vol. 83, 2005, pp. 12751321; Ho, D., y Quinn K. "How Not to Lie with Judicial Votes: Misconceptions, Measurement, and Models", en California Law Review, Vol. 98, N³, 2010, pp. 822-830).

${ }^{4}$ Garoupa, N., Gili, M., y Gómez-Pomar, F., "Political Influence and Career Judges: An Empirical Analysis of Administrative Review by the Spanish Supreme Court", en Journal of Empirical Legal Studies, Vol. 9, No 4, 2012; Kapiszewski, D., y Taylor M., "Doing Courts Justice? Studying Judicial Politics in Latin America", en Perspectives in Politics, Vol. 64, 2008, p.741; Schneider, M., "Judicial Career Incentives and Court Performance: An Empirical Study of the German Labour Courts of Appeal”, en European Journal of Law E Economics, Vol. 20, 2005, p. 127; Franck, R., "Judicial Independence Under a Divided Polity: A Study of the Rulings of the French Constitutional Court, 1959-2006”, en Journal of Law, Economics and Organization, Vol. 25, 2009, p. 262. Entre nosotros, puede verse el estudio realizado por Verdugo, S., "Aportes del modelo 
difícil encontrar registros confiables acerca de las orientaciones políticas de los jueces, y las ideas kelsenianas tienden hacia una autonegación formalista del rol de la política al interior de los tribunales ${ }^{5}$. Una manera de resolver este puzle es distinguiendo entre cortes supremas y tribunales constitucionales. Las cortes supremas están compuestas mayormente por jueces de carrera, respecto de los cuales existe poca evidencia acerca de sus inclinaciones políticas. Por el contrario, los jueces de los tribunales constitucionales suelen tener una carrera política previa o, al menos, se trata de individuos cuyas inclinaciones pueden adivinarse a partir de sus carreras profesionales y académicas.

El Tribunal Constitucional chileno (TC) es un caso interesante desde esta perspectiva. Por más de 25 años el TC funcionó bajo el diseño de la Constitución de 1980, donde la mayoría de sus ministros provenían de la judicatura o tenían estrechos vínculos profesionales con la Corte Suprema (CS). Este diseño fue sustancialmente modificado por la reforma del 2005, aumentando el número de jueces nombrados por los poderes políticos (Presidente de la República, Congreso) y favoreciendo la entrada de ministros ajenos a la carrera judicial, con un perfil más bien académico. A primera vista, mientras el primero de estos cambios debiera haber gatillado un giro a la centro-izquierda dentro del TC, el segundo parecería tender hacia la neutralidad política.

Nuestro objetivo es examinar el comportamiento del TC antes y después de la reforma. Para ello nos enfocamos en los requerimientos por inconstitucionalidad de los decretos supremos y de los decretos con fuerza de ley, ya que generalmente reflejan una disputa política entre el Presidente de la República y la oposición parlamentaria ${ }^{6}$. Los resultados sugieren que el patrón de votación en el TC no está relacionado con la afiliación política de los jueces. Sin embargo, un TC mayoritariamente académico (posreforma) es significativamente menos deferente con el Poder Ejecutivo que un TC mayoritariamente judicial (prerreforma de 2005). Es interesante notar que el TC

de disidencias judiciales al sistema político: pluralismo judicial y debate democrático", en Revista de derecho de la Universidad Católica del Norte, Vol. 18, No 2, 2011, pp. 217-272.

${ }^{5}$ Cappelletti, M. y Cohen W., Comparative Constitutional Law, New York, Bobbs-Merrill, 1979, pp. 73-84. El Sistema de control constitucional basado en un Tribunal Constitucional fue desarrollado por Hans Kelsen en la primera mitad del siglo XX, el mismo autor que, ciertamente, ha tenido influencia en la teoría formalista y positivista del Derecho. Ver, por ejemplo, Kelsen, H., General Theory of Law and State, Russell \& Russell, New York, 1961; Kelsen, H., Pure Theory of Law, University of California Press, Berkeley, 1967. Si se sigue la perspectiva kelseniana clásica acerca de los tribunales constitucionales, estos se entienden solo como un árbitro que resuelve problemas de potestades entre el Ejecutivo y el Congreso. Rousseau, D., La Justice Constitutionnelle en Europe, Montchrestien, Paris, 1992. Rousseau (1992); Favoreu, L., Levasseur, A. y Ward R., Constitutional Courts, Baton Rouge: Center of Civil Law Studies, LSU, 2011; Ginsburg, T., Judicial Review in New Democracies. Constitutional Courts in Asian Cases, Cambridge University Press, New York, 2003. En su origen, la función de estos tribunales no era proteger los derechos individuales ni promover las ideas encarnadas en la Constitución, sino determinar qué poder público tenía facultad para actuar en un caso particular. De manera similar, la interpretación del Derecho se concibe como una tarea relativamente mecánica, separada de la política y de otros intereses.

${ }^{6}$ Investigaciones recientes han demostrado que los jueces de carrera tienden a favorecer al Poder Ejecutivo en este tipo de disputas, aun cuando sea difícil determinar la afiliación política de los jueces. Ver, Garoupa, Gili y Gómez-Pomar (nota $N^{\circ}$ 7). Respecto de las distinciones entre los tipos de control constitucional, ver Cappelletti y Cohen (nota $\mathrm{N}^{\circ} 8$ ), pp. 73-84. 
prerreforma también era más propenso a decidir los casos de manera unánime, mientas que el TC posreforma tiene un registro mayor de votos disidentes. En nuestra opinión, estos resultados están en sintonía con la literatura cualitativa acerca del TC y las cortes chilenas en general. En Chile, los jueces de carrera tienen una reputación de ser deferentes con el poder político y de esconder sus pensamientos individuales detrás de sentencias unánimes. Sin embargo, esta actitud de los jueces va más allá de la afiliación política ${ }^{7}$. Por lo anterior, argumentamos que los efectos de la reforma no responden a un cambio mecánico en la inclinación política de los jueces, sino que a la evolución de la cultura jurídica subyacente. Entre otras ventajas, esta aproximación permite explicar un aspecto que ha tenido perpleja a nuestra comunidad jurídica: aunque la reforma de 2005 incrementó el número de jueces afiliados a la centro-izquierda, la primera administración de Bachelet enfrentó un nivel de activismo inédito por parte del TC, donde aun los jueces que habían tenido una carrera política previa con la Concertación votaron en contra de los intereses del gobierno.

Los principales estudios empíricos previos respecto del TC chileno son los de Royce Carroll y Lydia Tiede. Estos trabajos sugieren que el TC habría sido relativamente menos deferente con el gobierno en casos de requerimientos parlamentarios, y que el nivel de deferencia se habría incrementado después de la reforma de $2005^{8}$. Nuestros resultados muestran exactamente lo contrario, debido a tres grupos de diferencias metodológicas. En primer lugar, ellos analizaron todas las fuentes disponibles de control constitucional, mientras nosotros solo limitamos nuestro estudio a las disputas entre Presidente de la República y oposición parlamentaria. Según se explica más adelante, ello llevó a que Carrol y Tiede consideraran conjuntamente dos grupos de sentencias que son técnica y sustancialmente diferentes. En segundo lugar, nuestra variable de respuesta considera si el juez vota con la mayoría o con la minoría, mientras que Carroll y Tiede solo evaluaron si el juez estaba o no por declarar la inconstitucionalidad. Considerando que la reforma de 2005 incrementó la frecuencia de votos disidentes, tanto a favor como en contra de la declaración de inconstitucionalidad, es necesario controlar las interacciones internas del tribunal para evitar subestimar los resultados. En tercer lugar, Carroll

${ }^{7}$ Los jueces chilenos eran generalmente deferentes con el Ejecutivo durante el siglo XX, independientemente de que el gobierno promoviera políticas conservadoras o liberales. La explicación común en la literatura es que los jueces chilenos han aprendido a ser deferentes gracias a intervenciones traumáticas del Poder Ejecutivo, las que incluyen amenazas, detenciones ilegales e incluso enviando al presidente de la CS a un campo de concentración. Atinente a este tipo de explicaciones y otras, ver Correa Sutil, J., "No Victorious Army Has Ever Been Prosecuted: The Unsettled Story of Transitional Justice in Chile”, en McAdams J. (ed.), Transitional Justice and the Rule of Law in New Democracies, University of Notre Dame Press, Notre Dame, 1997, pp. 123-54; Hilbink, L., Judges Beyond Politics in Democracy and Dictatorship: Lessons from Chile, Cambridge University Press, New York, 2007; Zapata, P., La jurisprudencia del Tribunal Constitucional, Biblioteca Americana Santiago, Valparaíso, 2002; Couso, J., "The politics of Judicial Review in Chile in the Era of Democratic Transition, 1990-2002”, en Democratization, Vol. 10, No 4, 2003, pp. 70-91.

${ }^{8}$ Carroll, R. y Tiede L., "Judicial Behavior on the Chilean Constitutional Tribunal", en Journal of Empirical Legal Studies, Vol. 8, No 4, 2011, pp. 873-874; y, Carroll, R., y Tiede, L., "Ideological Voting on Chile's Constitutional Tribunal: Dissent Coalitions in the Adjudication of Rights", en Journal of Human Rights, Vol. $11 \mathrm{~N}^{\circ}$ 1, 2012, pp. 85-105. 
y Tiede basan su estudio en la inclinación política de las instituciones que participan en el nombramiento de los jueces, mientras que nosotros construimos nuestra variable explicativa utilizando datos explícitos acerca del perfil y experiencia profesional de los jueces. Nuestra metodología es preferible, porque los compromisos institucionales del período que vino después de la dictadura militar, incluyendo algunas prácticas implícitas en el Senado chileno, hacen que los mecanismos de designación sean un mal indicio para medir la afiliación política de los jueces.

El trabajo se divide de la siguiente manera. En la sección siguiente (II) resumiremos brevemente la evolución del TC y los mayores cambios que introdujo la reforma de 2005. En la tercera sección (III) explicaremos nuestro marco analítico, así como las variables de respuesta y explicativas del análisis. En la cuarta parte (IV) describiremos las preferencias de los jueces y mostraremos que, después de la reforma de 2005, el TC cambió hacia posiciones menos deferentes. En quinto lugar (V), argumentaremos que los cambios en el comportamiento del TC se relacionan con el enroque entre jueces de carrera y jueces académicos. Para concluir (VI), ofreceremos algunos comentarios finales. Con la finalidad de facilitar la lectura del trabajo, los resultados del análisis estadístico y otros aspectos técnicos han sido incluidos en un anexo?.

\section{El Tribunal Constitucional y LA Reforma DE 2005}

El TC chileno fue creado en $1970^{10}$. Luego de un breve período de funcionamiento fue disuelto por la dictadura militar en 1973, para luego ser reestablecido en la Constitución de $1980^{11}$. Bajo este diseño institucional, el TC tenía siete ministros

9 Tanto el anexo como la base de datos y el código necesaria para replicar el análisis se encuentran disponibles en la página http://works.bepress.com/dpardow/.

${ }^{10}$ Originalmente el TC fue creado para mediar entre las disputas políticas entre los diferentes poderes políticos. Friedler, E., "Judicial Review in Chile", en Southwestern Journal of Law E Trade in the Americas, Vol. 7, 2000, p. 321. En vez de defender derechos fundamentales, el propósito del TC era sostener los poderes reguladores y legislativos entregados al Ejecutivo por la misma reforma que creó el TC. Couso, J., "Models of Democracy and Models of Constitutionalism: The Case of Chile's Constitutional Court, 1970-2010", en Texas Law Review, Vol. 89, 2010, pp. 1529-1530.

${ }^{11}$ En este segundo periodo, que va de 1980 a 2005, el TC fue concebido como un mecanismo para preservar las instituciones contenidas en la Constitución dictada por el régimen de Pinochet. Relacionado con esto, ver Ribera, T., "Función y Composición del Tribunal Constitucional de 1980", en Revista Estudios Públicos, Vol. 27, 1987, pp. 77-112; Friedler (nota No 14), p. 321-347; Ríos, L., "El Nuevo Tribunal Constitucional”, en Zúñiga F. (ed.), Reforma Constitucional, Lexis Nexis, Santiago, 2005, pp. 627-650; y Mac-Clure, L., "Tribunal Constitucional y los Derechos: La Discusión Pendiente”, en Sierra L. (ed.), Frente a las Mayorías. Leyes Supramayoritarias y el Tribunal Constitucional en Chile, Centro de Estudios Públicos, Santiago, 2011, pp. 169-275. Para Hilbink, lo arraigado de la tradición del formalismo jurídico entre los jueces chilenos fue algo útil para los líderes del régimen militar (Hilbink, L., "The Constituted Nature of Constituents Interests Historical and Ideational Factors in Judicial Empowerment", en Political Research Quarterly, Vol. 62, No 4, 2009, pp. 788-792). Ello se debe a que, por una parte, el régimen estaba intentando construir una imagen de legitimidad legalista y, por la otra, a que las Cortes fueron vistas como un mecanismo útil (apolítico, imparcial) para defender la obra del régimen luego de volver a la democracia. Ver Andrade, 
que duraban ocho años con la posibilidad de renovarse en sus funciones. La CS elegía tres ministros del TC de entre sus propios miembros, los que se mantenían en ambos cargos de forma paralela, mientras el Presidente de la República y el Senado elegían un ministro cada uno. El Consejo de Seguridad Nacional (COSENA), por su parte, nombraba los otros dos jueces.

Este proceso de selección estaba diseñado para reducir la polarización del TC, promoviendo el consenso y la unanimidad en la resolución de las disputas internas ${ }^{12}$. Resulta interesante que tanto durante la dictadura militar como en el período democrático anterior al 2005 el COSENA eligió mayoritariamente a ex ministros de la CS o abogados integrantes de la misma ${ }^{13}$. Ello, unido a que las nominaciones de la CS recaían en sus propios miembros, produjeron una mayoría de ministros con un perfil profesional marcado por la carrera judicial (esto es, jueces de carrera o bien individuos con marcados vínculos profesionales con la judicatura). Es admisible destacar que la fortaleza de los vínculos del TC con la judicatura eran considerados como algo positivo: una garantía de que la cultura legalista orientaría al tribunal hacia la deferencia con el Ejecutivo, manteniéndose al margen de toda disputa política ${ }^{14}$.

Hasta la reforma, el TC solo poseía poderes de control preventivo y abstracto respecto de proyectos de ley, así como también acerca de ciertos decretos. En el caso de los decretos, los casos eran llevados al TC por una oposición parlamentaria, bastando un mínimo de un cuarto de las cámaras ${ }^{15}$. Como se aprecia, este tipo de control cons-

C., "Tribunal Constitucional", en Cuadernos de Análisis Jurídico, Universidad Diego Portales, No 31, 1996, pp. 277-309; Valenzuela, E., El Tribunal Constitucional de Chile y las Reformas que se analizan en el Congreso Nacional, Tribunal Constitucional No 3, Santiago, 1999; Barros, R., Constitutionalism and Dictatorship: Pinochet, the Junta, and the 1980 Constitution, Cambridge University Press, New York, 2002.

${ }^{12}$ Couso, J., "The politics of Judicial Review in Chile in the Era of Democratic Transition, 1990-2002", en Democratization, Vol. 10, N 4, 2003, pp. 70-91; Ríos (nota $\mathrm{N}^{\circ} 15$ ) pp. 627-650; Hilbink (nota $\mathrm{N}^{\circ} 12$ ).

13 Aparentemente, este compromiso obedeció a que los militares se vieron forzados a negociar los nombramientos con la oposición naciente y los individuos vinculados a la judicatura eran vistos como una opción neutral. Ver, Cavallo, A., La Historia Oculta de la Transición: Chile 1990-1998, Grijalbo, Santiago, 1998, pp. 125-138; Barros (nota $\mathrm{N}^{\circ}$ 15), pp. 234-240. Curiosamente, sin embargo, los ministros del TC nombrados por los militares jugaron un rol fundamental en establecer las condiciones para el plebiscito donde el régimen de Pinochet fue finalmente derrotado.

${ }^{14}$ Correa Sutil, J., "No Victorious Army Has Ever Been Prosecuted: The Unsettled Story of Transitional Justice in Chile", en McAdams J. (ed.), Transitional Justice and the Rule of Law in New Democracies, University of Notre Dame Press, Notre Dame, 1997, pp. 123-54; Couso, J., "The politics of Judicial Review in Chile in the Era of Democratic Transition, 1990-2002”, en Democratization, Vol. 10, No 4, 2003, pp. 70-91, Hilbink (nota No 12); Couso, J. y Hilbink L., "From Quietism to Incipient Activism", en Helmke G. y Rios-Figueroa J. (eds.), In Courts in Latin America, Cambridge University Press, New York, 2011, pp. 99-127. Con todo, razones de elección racional también pudieron haber jugado un rol relevante. Los jueces tenían la posibilidad de ser renovados en sus funciones, con lo que un proceso de fidelización resulta plausible (Andrade, C., "Tribunal Constitucional”, en Cuadernos de Análisis Jurídico, Universidad Diego Portales, N 31, 1996, pp. 277-309; Ribera, T., "Función y Composición del Tribunal Constitucional de 1980”, en Revista Estudios Públicos, Vol. 27, 1987, pp. 77-112; Valenzuela (nota $\mathrm{N}^{\circ} 15$ ).

15 Por "decretos" nos referimos tanto al control de los decretos con fuerza de ley (DFL) como a los decretos supremos, ya que en ambos tiene lugar la hipótesis donde el Presidente disputa la licitud de una regulación frente a un requerimiento de la oposición parlamentaria. Aunque existe una discusión académica 
titucional lleva implícita una controversia de intereses políticos entre el Jefe de Estado y la oposición, situación que no necesariamente ocurre tratándose del control de los proyectos de ley ${ }^{16}$. Por esta razón, el control de los decretos vuelve a este tipo de casos especialmente interesantes para evaluar la posibilidad de que existan preferencias políticas entre los jueces del $\mathrm{TC}^{17}$.

Acogiendo las críticas que se formulaban al sistema dual de control constitucional (donde el TC ejercía el control preventivo y la CS el represivo), la reforma de 2005 concentró en el TC todos los poderes de control sobre la ley ${ }^{18}$. Junto con ello, la reforma también cambió la composición del TC, el procedimiento de selección y los tiempos de duración en el cargo de ministro. Una primera consecuencia de la reforma fue que las instituciones ligadas al mundo militar perdieron toda influencia en el proceso de designación de jueces ${ }^{19}$. La CS, por su parte, mantuvo su poder para nombrar tres ministros,

en torno a la capacidad del TC para declarar la inconstitucionalidad de decretos, el TC siempre ha entendido que tiene dicho poder de control y las objeciones no han pasado de ser opiniones disidentes al interior del tribunal. Ver, García, A. M., "Control de Constitucionalidad de los Decretos Supremos", en Silva M. P. (ed.), Derechos Fundamentales y Justicia Constitucional, Thomson Reuters, Santiago, pp. 151-163, 2012; Cazor, K., "Nuevo Artículo 93 Número 16: Un Enfoque Más Coherente en Torno al Control de los Decretos Supremos por Parte del Tribunal Constitucional”, en Zúñiga F. (ed.), Reforma Constitucional, Lexis Nexis, Santiago, 2005, pp. 399-414).

${ }^{16}$ En el caso del control preventivo de las leyes, normalmente hay controversias donde el Presidente de la República puede no ser parte (quórums, ideas matrices, etc.). Además, los requerimientos contra proyectos de ley frecuentemente no impiden que el proyecto sea aprobado, o bien se refieren a aspectos formales que solo afectan el proyecto de manera tangencial. Scribner, D., "The Judicialization of (Separation of Powers) Politics: Lessons from Chile", en Journal of Politics in Latin America, Vol. 2, No 3, 2010 , p. 73.

${ }^{17}$ Ver, Navia, P. y Ríos-Figueroa J., "The Constitutional Adjudication Mosaic of Latin America”, en Comparative Political Studies, Vol. 38, No 2, 2005, pp. 189-217; Gómez, G., "La Reforma Constitucional a la Jurisdicción Constitucional”, en Zúñiga F. (ed.), Reforma Constitucional, Lexis Nexis, Santiago, 2005, p. 183; Cazor, K., "La Jurisdicción Constitucional en Chile", en Revista de Derecho de la Universidad Austral, Vol. 12, 2001, p. 413. Típicamente, durante el período incluido en este estudio (1990-2010) este tipo de control de decretos fue originado a propósito de algún requerimiento presentado por la Alianza en contra de un Poder Ejecutivo controlado por la Concertación.

${ }^{18}$ Ello parece convertir al TC en la autoridad más importante en materia de interpretación constitucional. Ver, Cazor, K., "La Jurisdicción Constitucional en Chile", en Revista de Derecho de la Universidad Austral, Vol. 12, 2001, pp. 91-106 y Silva, L., “¿Es el Tribunal Constitucional el supremo intérprete de la Constitución?”, en Revista de Derecho de la Universidad Católica de Valparaíso, Vol. 38, 2012, pp. 573-616. Es admisible agregar que el cambio incrementó sustancialmente la carga de trabajo del TC: antes conocía un promedio inferior a 50 casos anuales, mientras que los años inmediatamente siguientes a la reforma implicaron un promedio superior a 200 casos (Carroll, R. y Tiede L., "Judicial Behavior on the Chilean Constitutional Tribunal”, en Journal of Empirical Legal Studies, Vol. 8, No 4, 2011, pp. 859-860). Durante el 2010 ingresaron 304 casos, de ellos 259 correspondieron a casos de control represivo (Tribunal Constitucional, 2011, Cuenta Pública del Presidente del Tribunal Constitucional 2010, pp. 16-17).

${ }^{19}$ La reforma fue parte de un acuerdo político más amplio entre el gobierno del presidente Lagos y la oposición, donde la idea central era eliminar los denominados "enclaves autoritarios", dentro de los cuales estaban los poderes del COSENA para nombrar jueces del TC. Ver, Huneeus, C., "La Democracia Presidencial en Chile", en Persona y Sociedad, Vol. 19, No 2, 2005, pp. 11-53; Gómez (nota No 19), p. 413; Mac-Clure, L., “Tribunal Constitucional y los Derechos: La Discusión Pendiente”, en Sierra L. (ed.), Frente a las Mayorías. Leyes Supramayoritarias y el Tribunal Constitucional en Chile, Centro de Estudios Públicos, Santiago, 2011, pp. 169-275. 
pero al convertirse en una posición de tiempo completo, ellos ya no podrían ser parte de la propia CS. Esto, a su vez, fomentó que el nombramiento de jueces con un perfil más académico viniera a reemplazar a los jueces de carrera ${ }^{20}$. Por último, se fortalecieron los nombramientos de origen político, entregándole al Presidente de la República la facultad para designar tres ministros, y al Congreso la facultad de designar otros cuatro (dos por parte el Senado, y dos por la Cámara de Diputados con ratificación del Senado) ${ }^{21}$. En definitiva, el número total de jueces aumentó de 7 a 10, estableciendo que la duración del cargo sería de nueve años no renovables ${ }^{22}$.

Como ya adelantamos, antes de la reforma de 2005 el TC era notoriamente deferente con el Presidente de la República, y dictaba sus sentencias generalmente de manera unánime. Debido a la reputación legalista de los jueces chilenos, ambos comportamientos eran considerados como una consecuencia lógica de la manera en que el TC estaba compuesto, con una mayoría de ministros cercanos al mundo judicial ${ }^{23}$. Los cambios de la reforma de 2005 redujeron la influencia directa de la CS, y también incrementaron el origen político de los nombramientos. Sin embargo, la literatura parece enfocarse mucho más en esta última consecuencia. Algunos autores, particularmente mediante estudios cualitativos de casos, concluyen que el TC se encuentra avanzando hacia un incipiente activismo $^{24}$. Al contrario, el único estudio cuantitativo disponible hasta el momento sostiene que el nivel de activismo por parte del tribunal habría bajado después de la reforma ${ }^{25}$. La razón para esta diferencia es el tipo de casos analizados. Los estudios empíricos examinan la totalidad de sentencias del TC, mientras que los estudios cualitativos

${ }^{20}$ La reforma no prohíbe explícitamente que puedan nombrarse jueces de carrera, pero un juez de la CS no podría ejercer ambos cargos de manera coetánea. Ello generó que la práctica se tradujera en nombrar a abogados de cierto prestigio académico, pero no a jueces de carrera (difícilmente un ministro de la CS renunciaría para ser designado en el TC). Ver, Gómez (nota $\mathrm{N}^{\circ} 19$ ), p. 656.

21 Es posible precisar que, si bien la reforma de 2005 eliminó los nombramientos por parte del COSENA, dos jueces previamente nombrados por esta institución permanecieron en el TC hasta el 2010 (Cea y Colombo).Ver, Carroll y Tiede, nota $\mathrm{N}^{\circ} 24$, pp. 862-864.

${ }^{22}$ Este plazo es más largo que el establecido originalmente por la Constitución de 1980. El objetivo de eliminar la posibilidad de renovación era evitar que se transformase en una herramienta de presión política (Gómez, nota $\mathrm{N}^{\circ}$ 19, p. 657). Debe tenerse en cuenta, no obstante, que algunos de los jueces de nuestra muestra fueron nominados por períodos cortos y renovables, conforme a ciertas normas transitorias de la reforma de 2005. Este fue el caso de los ministros Correa, Venegas, Viera-Gallo, Navarro, Aróstica y Peña.

${ }^{23}$ Correa (nota $N^{\circ} 13$ ), pp. 123-54; Zapata (nota $N^{\circ} 12$ ); Couso (nota $N^{\circ} 12$ ), pp. 70-91; Hilbink (nota $\mathrm{N}^{\circ} 12$ ); Scribner (nota $\mathrm{N}^{\circ} 19$ ), p. 73.

${ }^{24}$ Couso y Hilbink (nota $\mathrm{N}^{\circ} 18$ ), p. 121. En su versión más sólida, este argumento considera que el movimiento del TC ha sido hacia la derecha, hacia posiciones más conservadoras (Bordalí, A. y Zúñiga,Y., "Análisis del Fallo del Tribunal Constitucional sobre la Píldora del Día Después" en Anuario de Derechos Humanos, Vol. 5, 2009, pp. 178-179). Se hace presente que, para efectos de este artículo, el concepto de activismo se refiere al nivel de deferencia con el Presidente de la República. Este concepto de activismo es diferente al utilizado por la literatura en otras sedes. Ver, García J. y Verdugo S., Activismo Judicial en Chile. ¿Hacia el Gobierno de los Jueces?, Libertad y Desarrollo, 2013.

${ }^{25}$ Este fue el caso del estudio de Royce Carroll y Lydia Tiede mencionado anteriormente ("the reform did not correspond to a sizable difference in the overall degree of support for unconstitutional rulings, and indeed such rulings declined overall”, Carroll y Tiede, nota No 24, pp. 873-874). 
solo analizan algunos casos de relevancia pública ${ }^{26}$. Curiosamente, sin embargo, los dos casos más analizados por la literatura cualitativa tratan acerca de decretos presidenciales. Por esta razón, una de las hipótesis a testear más adelante será si la reforma de 2005 ha provocado un cambio sustancial en el balance institucional de poderes, aun cuando este efecto sea estadísticamente irrelevante al mirar el universo total de casos.

\section{MARCO CONCEPTUAL}

Nuestra muestra incluye el universo total de requerimientos en contra de un decreto presidencial entre 1990 y 2010, esto es, desde el retorno a la democracia hasta el término del gobierno de Bachelet ${ }^{27}$. El voto individual de los jueces constituye la unidad de análisis, resultando en 199 observaciones hechas en relación con 32 sentencias $^{28}$.

La literatura ha desarrollado tres métodos para aproximarse a este tipo de datos: la codificación direccional (directional coding), los coeficientes de Pritchet y el anclaje bayesiano (Bayesian anchoring). El primero implica traducir el resultado del caso en una dimensión relevante para el análisis, típicamente en un eje "izquierda/derecha" o "liberal/ conservador" 29 . Así, por ejemplo, un voto por declarar la inconstitucionalidad de un precepto revelaría una preferencia a expandir el alcance de los derechos fundamentales (y por ende, liberal), mientras que una decisión a favor de la constitucionalidad significaría una inclinación hacia preservar el statu quo (y por ende, conservador). En contraste, los dos segundos métodos agrupan a los jueces que tienden a votar juntos, independientemente del resultado de la sentencia. De este modo, si se observa un grupo de jueces formando coaliciones de votación, el análisis intentará reflejar una relación exógena entre la cohesión de este grupo de jueces y su nivel de afinidad política.

Una desventaja de la codificación direccional es que requiere determinar la manera en que se codificará el resultado de la sentencia (constitucional/inconstitucional) de manera ex ante, identificando el resultado en el tipo de preferencia que se atribuye a los jueces individuales (liberal/conservador, izquierda/derecha, etc. ${ }^{30}$. Además, la cardinalidad de

${ }^{26}$ Estos análisis han encontrado dos tipos de casos donde los intereses políticos en juego eran particularmente altos. Así sucede con el denominado caso de la "píldora del día después” y el caso relativo al financiamiento del Transantiago. Ver, Couso y Hilbink (nota $\mathrm{N}^{\circ} 18$ ), pp. 118-121.

${ }^{27}$ Hemos excluido el período anterior a 1990 por tratarse de un contexto político diferente, y también el período posterior a 2010, ya que los datos no se encuentran disponibles en su totalidad. Hemos excluido, finalmente, las sentencias dictadas durante el primer período del TC (1970-1973), ya que el diseño institucional del TC era completamente diferente.

28 Además de excluir del análisis el control preventivo de las leyes, es posible señalar que también excluimos las acciones de inaplicabilidad e inconstitucionalidad dirigidas en contra de preceptos legales vigentes, ya que ellas aparecieron después de la reforma de 2005 y no podemos compararlas con la actividad previa del TC.

${ }^{29}$ Segal, J. y Spaeth H., The Supreme Court and the Attitudinal Model Revisited, Cambridge University Press, Cambridge, 2002, pp. 215-228.

${ }^{30}$ Por ello, la fortaleza de los resultados dependerá de cuán robusta sea la clasificación implícita. Ver, Ho and Quinn (nota $N^{\circ}$ 6), p. 846. 
la escala de valoración es típicamente problemática y los resultados menos intuitivos. La mayoría de estos problemas pueden eludirse mediante la metodología bayesiana o los coeficientes de Pritchett, ya que no requiere de una concepción previa para interpretar el significado político de los votos de los jueces. El problema es que, por definición, ambos métodos solo funcionan con casos donde existen sentencias divididas ${ }^{31}$.

Nuestro modelo implementa un procedimiento de codificación direccional, aunque lo hacemos de una manera que permite identificar las interacciones internas del TC. Como se muestra en la Figura 1, el voto de cada juez es modelado en un árbol de decisión que implica dos preguntas relacionadas: la primera es si el juez cree que el decreto es constitucional, y la segunda es si el juez prefiere posicionarse con la mayoría o con la minoría ${ }^{32}$. Para cada una de estas preguntas existe una variable binaria, de modo que su interacción produce una matriz dos por dos, con los siguientes cuatro valores únicos: (i) el Voto Tipo A representa un voto individual por la constitucionalidad del decreto, en circunstancias que el TC está dictando una sentencia por la inconstitucionalidad; (ii) el Voto Tipo $B$ representa un voto individual por la constitucionalidad del decreto, en circunstancias que el TC también está dictando una sentencia que lo declara constitucional; (iii) el Voto Tipo $C$ representa un voto individual por la inconstitucionalidad del decreto, en circunstancias que el TC también dicta una sentencia de inconstitucionalidad; y (iv) el Voto Tipo $D$ representa un voto individual por la inconstitucionalidad del decreto, en circunstancias que el TC está dictando una sentencia que lo declara constitucional.

Los Votos Tipo A y C tienen lugar cuando el decreto es considerado constitucional, mientras que los Votos Tipo B y D suponen una sentencia por la inconstitucionalidad. En nuestro modelo, los Votos Tipo A y C son interpretados como una preferencia en favor del Presidente (ya que defienden su decreto), y los Votos Tipo B y D son votos en contra del Presidente (ya que atacan su decreto). En lo relativo a la formación de coaliciones entre los jueces, los Votos Tipo A y D representan posiciones minoritarias, mientras que los Votos Tipo B y C representan posiciones mayoritarias. Esta metodología permite reunir las preferencias individuales al interior del TC en una sola dimensión, reflejando el grado de apoyo al gobierno incumbente. Particularmente, el grado de apoyo al gobierno es modelado como una función que decrece de izquierda a derecha (en términos formales, A [signo de preferencia] $\mathrm{B}$ [signo de preferencia] $\mathrm{C}$ [signo de preferencia] D) ${ }^{33}$.

${ }^{31}$ Garoupa, Gili y Gómez-Pomar (nota No 7), pp. 799-800.

32 No existe un orden particular entre estos dos niveles. Por ejemplo, un juez con una marcada preferencia individual debiera decidir primero acerca de la constitucionalidad del decreto, revisando después si su posición está en la mayoría o en la minoría. Por el contrario, un juez con una preferencia más débil seguramente intentará saber primero la opinión de sus colegas para después decidir aquella posición que mejor sintonice con sus creencias.

33 Aunque aceptemos que los votos pueden ser organizados en el orden propuesto más arriba, la cardinalidad sigue siendo problemática. En otras palabras, los votos disidentes pueden estar revelando una mayor intensidad de preferencia que los votos de mayoría, pero es difícil decir exactamente cuánto más firme sería dicha intensidad. Acerca del problema de cardinalidad en este tipo de modelos, Ho and Quinn (nota $\mathrm{N}^{\circ}$ 6), pp. 846-847. 


\section{Figura 1}

\section{Modelando el Tipo de Voto como preferencia política}

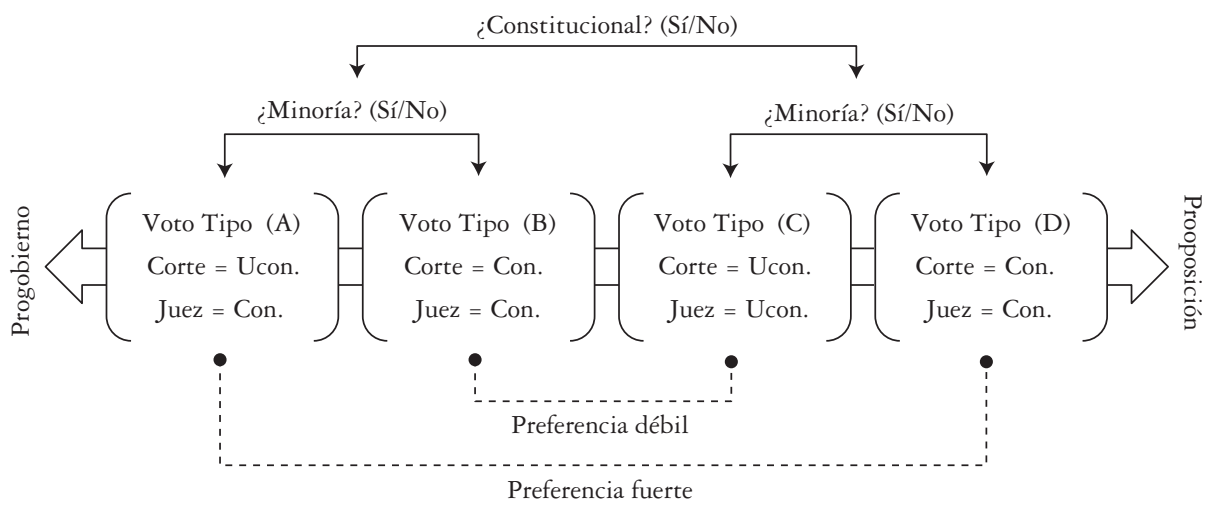

Esta figura muestra el Tipo de Voto como una decisión que envuelve dos preguntas relacionadas. El eje resultante representa el grado de deferencia frente al gobierno incumbente, decreciendo de izquierda a derecha. Los Tipos de Voto en los extremos representan opiniones disidentes, que asumimos revelan una preferencia más fuerte. Los Tipos de Voto en el centro representan a la mayoría del TC y, por consiguiente, sugieren una posición más moderada.

Algunos aspectos del modelo requieren mayor explicación. Primero, las opiniones disidentes revelan una preferencia individual más marcada que las opiniones individuales que están en la mayoría ${ }^{34}$. Más allá de las limitaciones de este enfoque, lo cierto es que el tamaño de la muestra es pequeño y la frecuencia de disidencias baja, lo que impide implementar metodologías más sofisticadas como el anclaje bayesiano o los coeficientes de Pritchett ${ }^{35}$. Enseguida, aunque la muestra proporciona una superposición casi perfecta con los 20 años en que Chile fue gobernado por la misma coalición de centro-izquierda, cualquier interpretación política debe proceder con cautela. Mientras nuestro modelo muestra el grado de deferencia con el gobierno, la escala no permite medir la coherencia

${ }^{34}$ La literatura distingue entre las preferencias políticas y lo que se denomina preferencia "disposicional" (dispositional preference). La preferencia política se asocia con el contenido de la opinión que dicta el tribunal, mientras que la preferencia disposicional refleja la posición ideal que al juez le gustaría elegir. En tribunales colegiados los jueces intercambian pérdidas políticas (apoyar o no la posición de la mayoría) en contra de pérdidas disposicionales (si la preferencia individual es consistente o no con su solución ideal). Nuestro modelo se focaliza en las pérdidas disposicionales, esto es, bajo qué condiciones un juez estaría dispuesto a separarse de la mayoría. Esta perspectiva, sin embargo, está sujeta a la crítica usual que se realiza a la teoría actitudinal: es una aproximación que jerarquiza una de las dimensiones de la disputa y que no considera las potenciales pérdidas políticas. Ver Segal y Spaeth (nota $\mathrm{N}^{\circ} 35$ ), pp. 54-58.

35 En nuestra muestra solo hay diez casos con decisiones divididas, lo que por sí solo hace difícil identificar coaliciones disidentes. La rotación de jueces también es alta, especialmente tratándose de los jueces que integraban la CS, siendo difícil encontrar exactamente el mismo grupo de ministros decidiendo más de un solo caso. 
con una filosofía política o moral. El grado de deferencia al gobierno debe entenderse como un indicio de las diferencias entre los jueces, pero estas diferencias también pueden obedecer a discrepancias respecto de la doctrina jurídica aplicable.

La variable explicativa está construida a partir de evidencia directa de afiliación política $^{36}$. Entre 1990 y 2008 se han nombrado 26 jueces al TC, y como se detalla en el anexo, en 13 casos pudimos encontrar antecedentes confiables. Siete jueces fueron clasificados como cercanos a la Concertación, incluyendo tres jueces que habían ocupado cargos públicos importantes bajo los gobiernos de Aylwin, Frey, Lagos y Bachelet. Otros tres tenían una afiliación explícita con el Partido Socialista, y el último ejerció como senador representando a dicha coalición. Los seis ministros restantes con antecedentes confiables de afiliación política fueron clasificados como cercanos a la Alianza. Cuatro de ellos ocuparon cargos públicos de importancia durante la dictadura militar, y otros dos fueron asesores parlamentarios de dicha coalición.

Respecto de la restante mitad de los jueces, sin embargo, carecemos de antecedentes suficientes como para presumir una afiliación política determinada. Desde una perspectiva profesional, cerca de la mitad de estos jueces corresponde a individuos que siguieron la carrera judicial, mientras que la otra mitad corresponde a abogados que siguieron una carrera académica. Como adelantábamos algunos párrafos atrás, tanto la judicatura como la academia han tenido perspectivas divergentes respecto del valor de las opiniones disidentes. Mientras los jueces tienden a ocultar sus creencias personales y buscar una suerte de objetividad institucional, la capacidad de disentir es vista como una virtud en el mundo académico ${ }^{37}$. Estas diferencias entre los perfiles judiciales y académicos nos llevaron a formalizar una nueva distinción, clasificando ambos tipos de ministros en diferentes grupos.

Una vez agrupados todos los jueces de perfil similar, es posible calcular la frecuencia con que cada grupo elige un Tipo de Voto en particular, tanto antes como después de la reforma. Por su parte, utilizando un modelo de regresión logístico también es posible evaluar si la frecuencia relativa revela una tendencia de votación estadísticamente significativa. Para este fin, utilizamos una variable binaria para cada Tipo de Voto y para cada perfil de juez. Además, una tercera variable binaria identifica los casos antes y después de la reforma de $2005^{38}$. El resultado de este proceso fue la creación de dos matrices independientes de cuatro por cuatro, con 32 interacciones posibles. La

\footnotetext{
${ }^{36}$ Como explicamos anteriormente, los mecanismos de designación son un indicio poco confiable para medir la afiliación política de los jueces. Los nombramientos realizados por instituciones ligadas al mundo militar privilegiaron la neutralidad política, mientras las designaciones hechas en el Congreso aplicaron un acuerdo implícito donde cada coalición mayoritaria elegía uno de los jueces. En consecuencia, no debiera sorprender que los jueces designados con dichos mecanismos se hayan comportado de manera moderada.

${ }^{37}$ Ver, por ejemplo, Couso (nota $\mathrm{N}^{\circ} 12$ ); Hilbink (nota $\mathrm{N}^{\circ} 12$ ).

38 Considerando que la reforma fue gradualmente implementada durante el 2006, el punto de corte lo pusimos en el primer caso decidido por el TC compuesto por 10 jueces (TC, sentencia rol N N $^{\circ}$ 45-06). Debería notarse, sin embargo, que el total de renovaciones de los jueces no se produjo sino hasta el 2007. El primer caso que ya no tuvo ministros de la CS votando en la decisión fue la sentencia rol N $\mathrm{N}^{\circ} 666-06$, la que fue decidida casi tres meses después.
} 
probabilidad de cada interacción fue evaluada con regresiones separadas, en las cuales el Tipo de Voto funcionó como la variable de respuesta y cada grupo de jueces como la variable explicativa. Para simplificar el análisis, solamente comentamos las frecuencias que resultaron estadísticamente significativas. En otras palabras, nos enfocamos en los resultados que muestran una preferencia real, una que efectivamente interpreta el comportamiento sistemático del TC.

\section{EFeCTOS DE LA REFORMA DE 2005 EN EL TIPO DE VOTO}

Antes de la reforma, el TC era un tribunal extremadamente deferente con el gobierno y generalmente emitía sus sentencias de manera unánime. Más del $80 \%$ de los votos individuales favorecieron al gobierno (Votos Tipo A y B), mientras que el $95 \%$ fueron votos de mayoría (Votos Tipo B y C). Lo anterior se puede observar en el panel izquierdo de la Figura 2, donde el Voto Tipo B aparece como la primera preferencia del TC. Curiosamente, el patrón es significativamente más débil en el escenario posterior a la reforma, según se muestra en el panel del centro. En otros términos, antes de la reforma hay una tendencia claramente establecida, pero después de la reforma esa tendencia desaparece. Aunque el Voto Tipo B permanece como la primera preferencia, la distancia con las restantes alternativas es significativamente más corta. En el escenario prerreforma, la frecuencia del voto mayoritario en favor del gobierno era mayor que la suma de todas las otras alternativas, mientras que en el escenario posreforma ocurre lo contrario.

La Figura 2 también ilustra el argumento que relaciona las actitudes del TC prerreforma con el hecho de que la mayoría de sus ministros fueran jueces de carrera. El panel de la izquierda muestra la distribución del tipo de voto en la CS, usando un conjunto diferente de casos donde el gobierno también actuó como parte ${ }^{39}$. Nuevamente la comparación visual es llamativa. El TC prerreforma parecía seguir el mismo patrón de votación que caracteriza a la CS. Después de la reforma, sin embargo, el patrón de deferencia y unanimidad se modifica sustancialmente, al punto que el dominio relativo del Voto Tipo B parece desaparecer. Por lo anterior, los cambios en el patrón de votación parecieran obedecer al decaimiento de la influencia de la CS como consecuencia de la reforma de 2005 .

${ }^{39}$ Los datos están tomados de Verdugo, S. y Ottone C., "Revisitando el Debate Sobre los Abogados Integrantes y la Independencia del Poder Judicial”, en Actualidad Jurídica, Universidad del Desarrollo, Vol. 27, 2012, pp. 199-219. Este trabajo incluye 318 votos individuales correspondientes a 92 casos decididos entre 2005 y 2011. Los casos consistían en demandas de indemnización de perjuicios en contra del Fisco, que llegaron a la CS luego de la apelación previa. Las sentencias fueron codificadas como favoreciendo al gobierno si es que la CS reducía el monto de la indemnización establecida por la Corte inferior, o si confirmaba el rechazo de la acción indemnizatoria. En los otros casos, la sentencia fue codificada como contraria al gobierno. 


\section{Figura 2}

Distribución del Tipo de Voto

(por reforma y tipo de tribunal)

(A) $\quad(\mathrm{B}) \quad$ (C) $\quad$ (D)

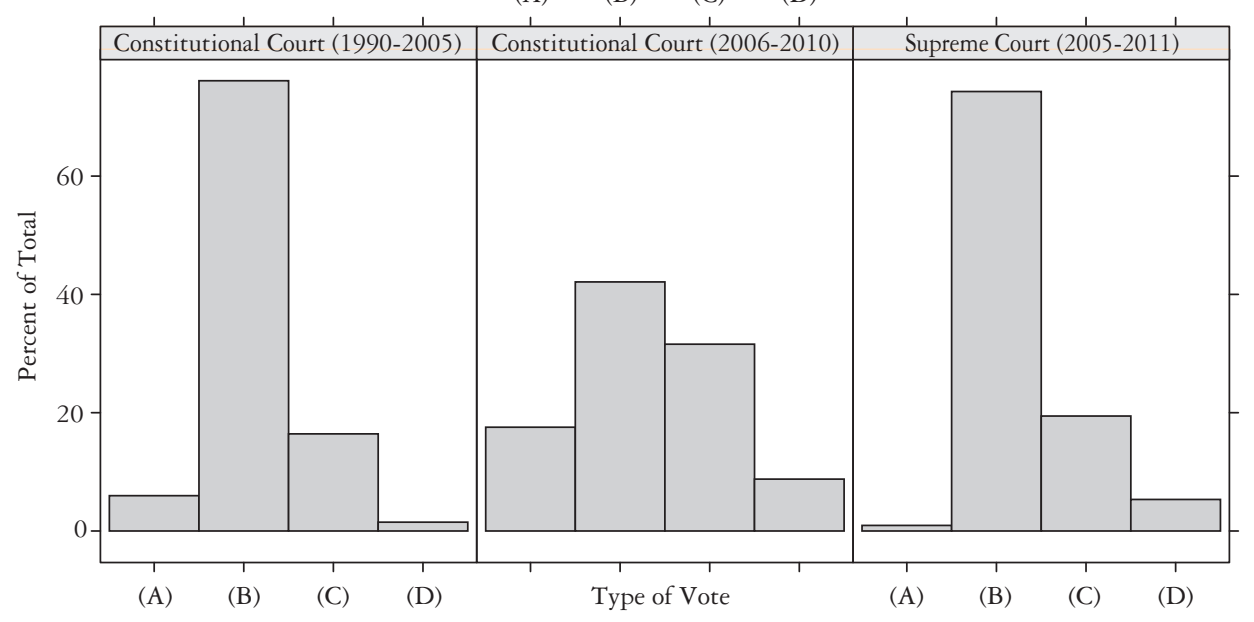

Las figuras ilustran la distribución del Tipo de Voto en tres escenarios diferentes. El Tipo de Voto está en el eje horizontal, mientras que el eje vertical muestra el porcentaje del total. La figura en la derecha representa la distribución del Tipo de Voto en el TC antes de la reforma, la figura en el centro hace lo propio con el TC después de la reforma, y la figura en la derecha representa la misma distribución en la CS. Los datos utilizados en esta última figura fueron tomados de Verdugo y Ottone (2013).

Después de la reforma la probabilidad de una sentencia contra el gobierno se duplica. Respecto de las interacciones al interior del TC, después de la reforma las sentencias unánimes son la mitad de probables que antes. Ambos movimientos están relacionados. Observando los promedios, la frecuencia con que ocurre un Voto Tipo B decrece desde $76 \%$ antes de la reforma a $50 \%$ después de la reforma, mientras que en los otros Tipos de Voto la frecuencia aumenta de manera pareja. Por lo demás, después de la reforma el error estándar aumenta al doble en todos los tipos de voto. En consecuencia, lo que antes de la reforma era evidencia de una tendencia hacia la deferencia y la unanimidad, después de la reforma se transforma en incertidumbre ${ }^{40}$.

${ }^{40}$ Los cambios provocados por la reforma son estadísticamente significativos mediante todos Tipos de Voto y grupos de jueces. El cambio de mayor magnitud está relacionado con la probabilidad de una sentencia dividida. La probabilidad de un voto disidente en favor del gobierno pasa a ser el doble después de la reforma (Voto Tipo A), mientras que la probabilidad de un voto disidente en contra del gobierno se vuelve cinco veces más grande (Voto Tipo D). Los cambios en la probabilidad de votos mayoritarios son más pequeños, pero también resultan significativos. Un voto mayoritario en contra del gobierno es 1,5 veces más probable después de la reforma (Voto Tipo C). Por su parte, las chances de un voto mayoritario en favor del gobierno decrecen sustancialmente en el escenario posreforma, reduciéndose a la mitad (Voto Tipo B). 
Es fácil observar por qué ciertos autores creen que el TC se ha movido hacia la derecha política. Es claro que el aumento de la probabilidad de los Votos Tipo C y D es mayor que el aumento de la probabilidad del Voto Tipo A. En nuestro eje de apoyo decreciente al gobierno incumbente, la fracción de los datos que se localizan en la mitad de la derecha aumenta sustancialmente. Sin embargo, debe considerarse que estos cambios son relevantes solo en términos relativos. El punto de partida es un TC altamente deferente y unánime, lo que por sí solo es una tendencia estadísticamente significativa. Sin embargo, el conjunto de preferencias resultantes son difíciles de interpretar. Aunque después de la reforma cada Tipo de Voto tiene una probabilidad de ocurrencia distinta, las diferencias se encuentran dentro del margen de error. En otras palabras, después de la reforma no podemos estar seguros acerca de cuáles son las preferencias reales del TC. Por ello, un movimiento a la derecha tiene el mismo respaldo de los datos que un movimiento hacia el centro político.

\section{V. ¿QUiÉN Y CÓMO CAMBIÓ DESPUÉS DE LA REFORMA?}

Los jueces de la CS pasaron de tener el mayor poder de votación colectivo antes de la reforma, a emitir únicamente un voto después de la reforma. Por el contrario, los jueces académicos fueron gradualmente ganando influencia. En el TC prerreforma los

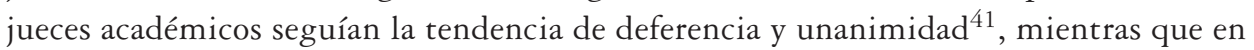
el TC posreforma esta tendencia desaparece ${ }^{42}$. En ambos escenarios, el comportamiento de los jueces académicos se asemeja al del TC en general.

Los jueces con una afiliación política explícita nos entregan otra tendencia interesante. Antes de la reforma, hay evidencia de un alineamiento entre la afiliación política del juez y su patrón de votación ${ }^{43}$. Casi un tercio de los votos de jueces afiliados a la Concertación fueron votos disidentes en favor del gobierno, mientras que un tercio de

41 Con todo, es importante aclarar que los resultados antes de la reforma están dominados por el comportamiento de un solo juez, Juan Colombo. Este juez tiene la mayor duración en la muestra, y entregó casi la mitad de los votos correspondientes a jueces académicos (20 votos antes de la reforma, representando un $75 \%$ del total; y 4 votos después de la reforma, representando $15 \%$ del total). Además, la clasificación de este juez es un caso límite: aunque no siguió una carrera judicial propiamente tal, Colombo es un árbitro reconocido y ha servido como abogado integrante en múltiples ocasiones.

${ }^{42}$ Mientras el juez Colombo mantuvo una tendencia similar en los dos períodos, sus pares se comportaron de manera diferente. Antes de la reforma, Colombo decidió solo cuatro casos junto con otro juez académico, Mario Verdugo. Tres de los casos fueron unánimes y favoreciendo al gobierno (TC, sentencias roles 253-97, 254-97 y 305-00). La sentencia restante fue dividida, pero ambos jueces actuaron favoreciendo al gobierno. Los otros tres jueces académicos fueron José Luis Cea, Enrique Navarro y Marisol Peña. El primero fue nombrado en 2002 y después en 2006. Como mostramos en el anexo, los tres evolucionaron hacia un patrón de votación menos deferente con el gobierno.

43 Mientras que la primera preferencia es siempre la misma para todos los perfiles de jueces (Voto Tipo B), la segunda preferencia parece seguir un eje político izquierda-derecha. En el análisis de regresión, la interacción entre el Voto Tipo A y el perfil Concertación es significativo, y algo similar sucede en la interacción entre el perfil asociado a la Alianza y el Voto Tipo C. 
los votos de los jueces afiliados a la Alianza fueron votos mayoritarios en contra del gobierno. Sin embargo, su comportamiento posreforma es difícil de explicar. En términos relativos, el número de votos de jueces relacionados con la Concertación se triplicó, al tiempo que el número de votos de jueces relacionados con la Alianza decreció dos tercios. Considerando el número total de votos antes de la reforma, los jueces de la Alianza superaban a sus pares de la Concertación en una proporción de 5 a 1 . Después de la reforma, la Concertación revirtió la situación situándose con una ventaja de 2 a $1^{44}$. Antes de la reforma los jueces afiliados a la Concertación eran una clara minoría, con solo $6 \%$ del total de votos. En el período siguiente los jueces afiliados a la Concertación se transformaron en la primera mayoría, con $40 \%$ del total de votos.

La realidad, sin embargo, va mucho más allá de estos números. Después de la reforma, ambas coaliciones tienen casi exactamente el mismo patrón de votación. La alineación entre afiliación política y tipo de voto desaparece, ya que tanto los jueces pro-Alianza como los jueces pro-Concertación carecen de una preferencia clara en el escenario posreforma. En el período prerreforma los jueces pro-Concertación nunca votaron en contra del gobierno. Por su parte, los jueces pro-Alianza rara vez fueron disidentes y, cuando lo fueron, nunca estuvieron en favor del gobierno. Ambos grupos tienen un tercio de votos disidentes posreforma. Los jueces que supuestamente representan la centro-izquierda votaron un cuarto de las veces en contra del gobierno que favoreció su nombramiento, mientras los jueces pro-Alianza emitieron votos disidentes en sentido contrario ${ }^{45}$.

Carroll y Tiede interpretan la ausencia de una tendencia clara como un signo de independencia ${ }^{46}$. Otros autores argumentan que existe un cambio en la cultura jurídica subyacente, donde una nueva concepción basada en los derechos constitucionales está ganando terreno ${ }^{47}$. Ambas ideas tienen apoyo en nuestros datos. Sabemos que antes de la reforma el TC era deferente con el gobierno y favorecía la unanimidad. También sabemos que ambas características eran más intensas en los patrones de votación de los jueces de la CS, lo que resulta consistente con la valoración que suele hacerse acerca de la cultura legalista del Poder Judicial. Finalmente, sabemos que la tendencia hacia la deferencia y unanimidad desaparecen cuando los jueces de carrera salen del TC. La última pieza del puzle es que incluso antes de la reforma, la deferencia y la unanimidad estaban correlacionadas con la fracción de jueces de la CS que decidían los casos.

${ }^{44} \mathrm{La}$ tendencia se revierte de nuevo luego del periodo incluido en nuestro estudio, debido a que el presidente Piñera nombró dos nuevos jueces asociados a la Alianza (Romero y Brahm).

45 Este comportamiento errático de los jueces ha sido largamente discutido en la prensa. Así por ejemplo, el juez Fernández (un democratacristiano y exministro de Defensa) fue objeto de muchas críticas por votar en contra del gobierno en el caso de la Píldora del día Después, y el juez Correa no fue renovado en su cargo luego de haber votado en contra del gobierno en el caso Transantiago.

${ }^{46}$ Carroll y Tiede (nota $\left.\mathrm{N}^{\circ} 24\right)$, p. 874.

${ }^{47}$ Couso y Hilbink (nota $\left.\mathrm{N}^{\circ} 18\right)$, p. 121. 


\section{Figura 3}

Fracción de jueces de carrera, unanimidad y constitucionalidad

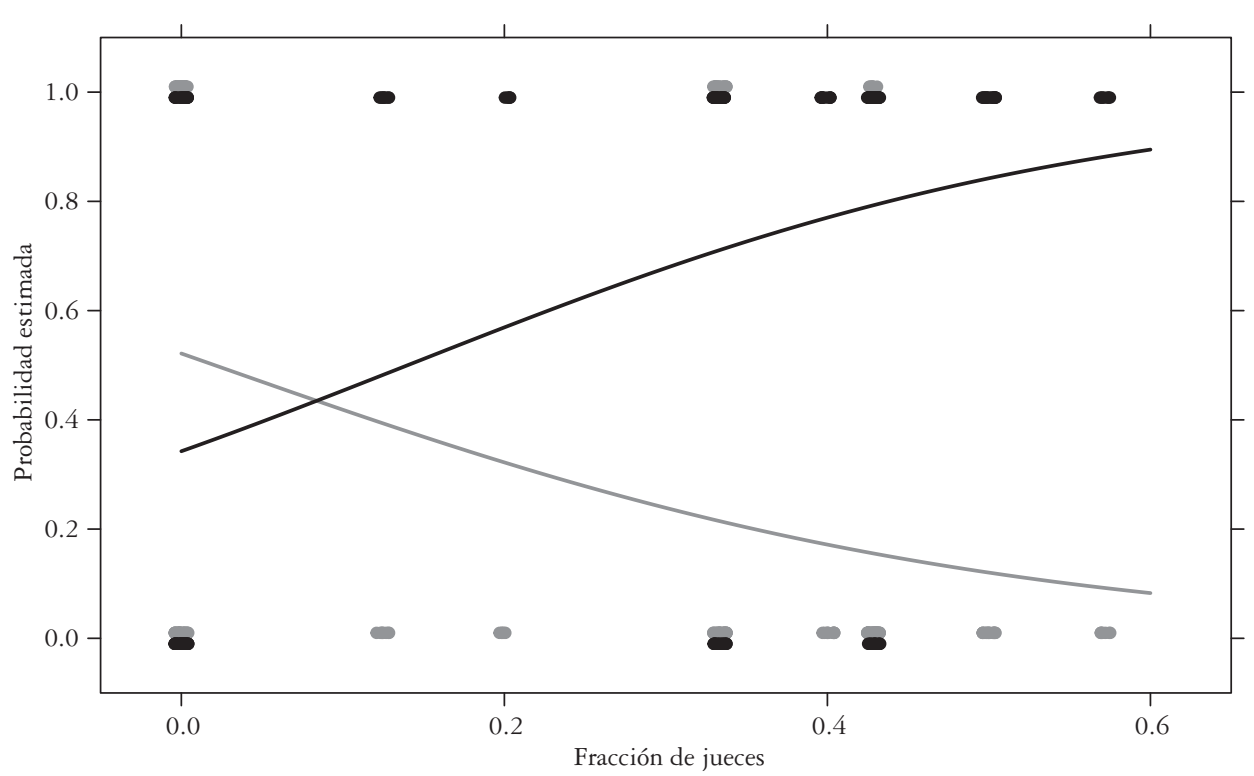

Esta figura muestra los cambios en las sentencias esperadas del TC, dependiendo de la fracción de jueces de carrera decidiendo los casos. El eje horizontal muestra la fracción de jueces de carrera y el eje vertical el resultado estimado. La línea ascendente representa la probabilidad de una sentencia unánime, y la línea descendente representa la probabilidad de una sentencia en contra del gobierno. Los puntos en los márgenes verticales son los casos de la muestra. Para permitir su visualización, los puntos están difuminados en el eje horizontal

Enfocarse en la dinámica de los mecanismos de designación, implica un problema metodológico que no habíamos abordado hasta el momento. En términos generales, la composición del TC varía debido a que es normal que algunos de sus miembros dejen temporalmente sus labores y se apliquen las reglas especiales de subrogación ${ }^{48}$. En varios casos de nuestra muestra, la ausencia de ciertos jueces tuvo una influencia importante en la composición del $\mathrm{TC}^{49}$. Desde esta perspectiva, incluso si la CS estaba autorizada a nombrar a 3 de los 7 jueces del TC, la proporción de jueces de carrera que decidía los casos varía entre $17 \%$ y $58 \%$. Esta variación en la composición del TC nos permite valorar la influencia real de los jueces de carrera de manera longitudinal, incluso antes de los cambios generados por la reforma.

48 Actualmente los suplentes son nombrados siguiendo un mecanismo similar al que se aplica para los jueces titulares. Sin embargo, antiguamente las ausencias eran llenadas mediante abogados integrantes, quienes eran designados por la mayoría del TC.

${ }^{49}$ En promedio, antes de la reforma había un caso por año relativo a este tipo de requerimiento, y la composición del TC para cada uno nunca era el mismo. 
El objetivo es entonces evaluar si la influencia decreciente de la CS entrega una explicación razonable para el abandono de la tendencia hacia la deferencia y unanimidad. Considerando que ambas circunstancias fueron registradas como variables binarias, la manera más fácil de examinar nuestra hipótesis es mediante una nueva serie de regresiones logísticas. La primera estima la probabilidad de una sentencia de inconstitucionalidad, utilizando el resultado del caso como variable de respuesta y la fracción de jueces de la CS como variable explicativa. La segunda estima la probabilidad de una sentencia unánime siguiendo un procedimiento similar.

Con relación a la probabilidad de una sentencia que declare la inconstitucionalidad, el coeficiente para la pendiente es estadísticamente significativo, mientras que el coeficiente para la ordenada en el origen no lo es ${ }^{50}$. La ordenada en el origen representa el TC posreforma, cuando los jueces de carrera ya no estaban presentes. Como hemos visto, el incremento de las posibilidades de votos mayoritarios y minoritarios en contra del gobierno es compensado en cierta medida por el aumento de la probabilidad de votos disidentes a favor del gobierno. Enseguida, el coeficiente de la pendiente tiene signo negativo. Ello muestra que la probabilidad de un fallo en contra del gobierno está negativamente correlacionada con la fracción de jueces de la CS resolviendo el caso. Cuanto mayor sea el número de jueces de carrera presentes en la vista de la causa, menor es la probabilidad de que el tribunal declare la inconstitucionalidad. En otras palabras, los resultados sugieren que la deferencia con el gobierno es una característica de los jueces de carrera, pero no necesariamente del TC.

En lo que se refiere a la tendencia a fallar por unanimidad, ambos coeficientes son significativos. Sin embargo, y al contrario del caso anterior, el coeficiente de la pendiente es positivo, indicando que la probabilidad de una sentencia unánime está positivamente correlacionada con la fracción de jueces de la CS. Cuanto mayor sea el número de jueces de carrera presentes en la vista de la causa, menor es la probabilidad de observar un voto disidente. Nuevamente los resultados sugieren que la tendencia hacia la unanimidad es una característica de los jueces de carrera, pero no necesariamente del TC.

En términos comparativos, los signos de los coeficientes son consistentes con el análisis hecho en las secciones previas. La ordenada en el origen representa al TC después de la reforma, teniendo una asociación positiva con la probabilidad de una sentencia en contra del gobierno y una asociación negativa con la probabilidad de una sentencia unánime. Por su parte, la pendiente representa al TC prerreforma y la asociación sigue la lógica contraria. Estas ideas están graficadas en la Figura 3. La línea ascendente, que representa el proceso interno de toma de decisiones por parte del tribunal comienza en la mitad inferior del eje vertical. Como se aprecia, la probabilidad de un fallo unánime en un TC sin jueces de carrera es cercana a $35 \%$, en circunstancias que cuando los jueces de carrera son mayoría dicha probabilidad supera el $85 \%$. Dicho de otro modo, en un tribunal preponderantemente académico las posibilidades de observar un voto

${ }^{50}$ Los resultados completos de ambos modelos están en el anexo, Tabla A-2. 
de disidencia son de $65 \%$, mientras que en un tribunal preponderantemente judicial son menores a $15 \%$.

Al contrario, la línea descendente representa el resultado del caso y comienza cerca de la mitad del eje vertical. Como se observó anteriormente, el TC actual solo puede ser considerado como activista cuando se le compara con su propia tendencia pasada. En casos donde los jueces de carrera están excluidos del tribunal, la probabilidad de un fallo en contra del gobierno es cercana a 50\%. Dicha probabilidad disminuye a medida que la proporción de jueces de carrera aumenta, hasta ubicarse en el rango de $10 \%$ cuando ellos son mayoría en el tribunal. Con todo, en su actual composición el TC carece de una tendencia clara. Un tribunal donde cada parte tiene $50 \%$ de posibilidades de ganar no pareciera ser particularmente sesgado, sino más bien todo lo contrario

\section{Observaciones finales}

Los estudios empíricos acerca del TC se han enfocado en el aumento del número de jueces nombrados por autoridades elegidas democráticamente (Congreso, Presidente de la República). Aun cuando este sea el efecto más importante de la reforma en el largo plazo, los cambios inmediatos en el comportamiento del TC se relacionan principalmente con la disminución de influencia del Poder Judicial. Desde esta perspectiva, el elemento más importante de la reforma fue transformar el trabajo de ministro del TC en una ocupación de dedicación exclusiva, lo que a su vez gatilló el enroque entre jueces de carrera y jueces académicos.

El nivel de deferencia con el gobierno efectivamente ha disminuido, pero es difícil interpretar este movimiento como un cambio en la orientación política del TC. Un cálculo mecánico de las supuestas preferencias políticas de los jueces lleva a la paradoja que enfrentó el gobierno de la presidenta Bachelet: el momento donde el número de aliados dentro del tribunal parecía mayor, fue precisamente cuando enfrentó mayor oposición. Aunque el TC haya incrementado su activismo en casos emblemáticos, no existe evidencia de un giro hacia la derecha política. De hecho, la tendencia hacia el activismo solo es significativa estadísticamente si se la compara con la actitud altamente deferente que tuvo el TC antes de la reforma. Hoy el TC carece de preferencias estadísticamente significativas, lo que resulta consistente con una idea de neutralidad política.

\section{BiBLIOGRAFÍA}

Andrade, C., "Tribunal Constitucional”, en Cuadernos de Análisis Jurídico, Universidad Diego Portales, $\mathrm{N}^{\circ} 31,1996$, pp. 277-309.

Barros, R., Constitutionalism and Dictatorship: Pinochet, the Junta, and the 1980 Constitution, Cambridge University Press, New York, 2002.

Batchis, W., "Constitutional Nihilism: Political Science and the Deconstruction of the Judiciary", en Rutgers Journal of Law \& Public Policy, Vol. 6, 2008, pp. 1-35. 
Bordalí, A. y Zúñiga, Y., "Análisis del Fallo del Tribunal Constitucional sobre la Píldora del Día Después”, en Anuario de Derechos Humanos, Vol. 5, 2009, pp. 173-182.

Brenner, S. y Spaeth H., "Ideological Position as a Variable in the Authoring of Dissenting Opinions on the Warren and Burger Courts", en American Politics Quarterly, Vol. 16, 1998, pp. 317-328.

Brenner, S. y Speath H., "Majority opinion assignaments and the maintenance of the original coalition on the Warren Court", en American Journal of Political Science, Vol. 32, 1988, pp. 72-81.

Brenner, S. y Spaeth H., Stare Indecisis: The Alteration of Precedent on the Supreme Court 19461992, Cambridge University Press, New York, 1995.

Cameron, Ch. y Kornhauser L., "Modeling Collegial Courts III: Adjudication Equilibria”, en Public Law Research, NYU School of Law, Vol. 9, 2009, pp. 9-29.

Cappelletti, M. y Cohen W., Comparative Constitutional Law, New York, Bobbs-Merrill, 1979.

Carroll, R. y Tiede L., "Judicial Behavior on the Chilean Constitutional Tribunal", en Journal of Empirical Legal Studies, Vol. 8, No 4, 2011, pp. 856-877.

Carroll, R. y Tiede L., "Ideological Voting on Chile's Constitutional Tribunal: Dissent Coalitions in the Adjudication of Rights", en Journal of Human Rights, Vol. 11, No 1, 2012, pp. 85-105.

Cavallo, A., La Historia Oculta de la Transición: Chile 1990-1998, Grijalbo, Santiago, 1998.

CAzor, K., "La Jurisdicción Constitucional en Chile", en Revista de Derecho de la Universidad Austral, Vol. 12, 2001, pp. 91-106.

Cazor, K., "Nuevo Artículo 93 Número 16: Un Enfoque Más Coherente en Torno al Control de los Decretos Supremos por Parte del Tribunal Constitucional”, en Zúñiga F. (ed.), Reforma Constitucional, Lexis Nexis, Santiago, 2005, pp. 399-414.

Cordero, E., "El Tribunal Constitucional y el Control de los Actos del Poder Ejecutivo", en Revista Chilena de Derecho, Vol. 20, 1993, pp. 755-762.

Correa Sutil, J., "No Victorious Army Has Ever Been Prosecuted: The Unsettled Story of Transitional Justice in Chile", en McAdams J. (ed.), Transitional Justice and the Rule of Law in New Democracies, University of Notre Dame Press, Notre Dame, 1997, pp. 123-54.

Couso, J., "The politics of Judicial Review in Chile in the Era of Democratic Transition, 19902002", en Democratization, Vol. 10, No 4, 2003, pp. 70-91.

Couso, J., "Models of Democracy and Models of Constitutionalism: The Case of Chile's Constitutional Court, 1970-2010", en Texas Law Review, Vol. 89, 2010, pp. 1517-1536.

Couso, J. y Hilbink L., "From Quietism to Incipient Activism”, en Helmke G. y Rios-Figueroa J. (eds.), In Courts in Latin America, Cambridge University Press, New York, 2011, pp. 99-127.

Cross, F., "Political Science and the New Legal Realism: A Case of Unfortunate Interdisciplinary Ignorance", en Nortbwestern University Law Review, Vol. 92, 1997, p. 251.

De Ramón, A., Biografías de Chilenos 1876-1973 Miembros de los Poderes Ejecutivo, Legislativo y Judicial, Ediciones Universidad Católica de Chile, Santiago, 1999.

Edwards, H. y Livermore M., "Pitfalls of Empirical Studies That Attempt to Understand the Factors Affecting Appellate Decisionmaking”, en Duke Law Journal, Vol. 58, 2008, pp. 1895-1990.

Epstern, L., Martin, A., Quinn K. y Segal J., "Circuit Effects: How the Norm of Federal Judicial Experience Biases the Supreme Court”, en University of Pennsylvania Law Review, Vol. 157, 2008, p. 833 .

Epstein, L. y Knight J., The Choices Justices Make, Congressional Quarterly Inc., Washington D.C., 1998.

Epstein, L., Segal J. y Spaeth H., "The Norm of Consensus on the U.S. Supreme Court", en American Journal of Political Science, Vol. 45, No 2, 2001, p. 362. 
Epstein, L., Landes W., y Posner R., "Why (and When) Judges Dissent: A Theoretical and Empirical Analysis", en Journal of Legal Analysis, Vol. 3, No 1, 2011, pp. 101-137.

Favoreu, L., Levasseur, A. y Ward R., Constitutional Courts, Baton Rouge: Center of Civil Law Studies, LSU, 2011.

Fernández, M., "La Teoría de la Ley Pantalla. A propósito de la Sentencia del Tribunal Constitucional sobre el Proyecto de la Ley Orgánica", en Nogueira H. (ed.), Temas de Derecho Procesal Constitucional, Centro de Estudios Constitucionales, Santiago, 2010, pp. 191-211.

Franck, R., "Judicial Independence Under a Divided Polity: A Study of the Rulings of the French Constitutional Court, 1959-2006", en Journal of Law, Economics and Organization, Vol. 25, 2009, p. 262.

Friedler, E., "Judicial Review in Chile", en Southwestern Journal of Law E Trade in the Americas, Vol. 7, 2000, pp. 321-347.

García, A. M ${ }^{a}$, "Control de Constitucionalidad de los Decretos Supremos", en Silva $M^{a}$ P. (ed.), Derechos Fundamentales y Justicia Constitucional, Thomson Reuters, Santiago, 2012, pp. 151-163.

Garoupa, N., Gili, M., y Gómez-Pomar, F., "Political Influence and Career Judges: An Empirical Analysis of Administrative Review by the Spanish Supreme Court", en Journal of Empirical Legal Studies, Vol. 9, No 4, 2012, pp. 795-826.

Garretón, R., 2011. "Chile: Perpetual Transition Under the Shadow of Pinochet", en De La Barra X. (ed.), Neoliberalisms Fractured Showcase, Vol. 3 of Studies inCritical Social Sciences Leiden: Brill, 2011, p. 73.

Ginsburg, T., Judicial Review in New Democracies. Constitutional Courts in Asian Cases, Cambridge University Press, New York, 2003.

Gómez, G., "La Reforma Constitucional a la Jurisdicción Constitucional”, en Zúñiga F. (ed.), Reforma Constitucional, Lexis Nexis, Santiago, 2005, pp. 651-684.

Guiloff, M., "La Remisión Normativa Como Estándar: Una Rearticulación Democrática del Control de Constitucionalidad de Decretos Supremos", en Cazor K. (ed.), Estudios Constitucionales, Lexis Nexis, Santiago, 2010, pp. 303-325.

Hilbink, L., Judges Beyond Politics in Democracy and Dictatorship: Lessons from Chile, Cambridge University Press, New York, 2007.

Hilbink, L., "The Constituted Nature of Constituents Interests Historical and Ideational Factors in Judicial Empowerment", en Political Research Quarterly, Vol. 62, No 4, 2009, pp. 781-797.

Ho, D., y Quinn K., "How Not to Lie with Judicial Votes: Misconceptions, Measurement, and Models", en California Law Review, Vol. 98, N 3, 2010, p. 813.

Huneeus, C., "La Democracia Presidencial en Chile", en Persona y Sociedad, Vol. 19, No 2, 2005 , pp. 11-53.

Kapiszewski, D., y Taylor M., "Doing Courts Justice? Studying Judicial Politics in Latin America", en Perspectives in Politics, Vol. 64, 2008, p. 741.

Kelsen, H., General Theory of Law and State, Russell \& Russell, New York, 1961.

Kelsen, H., Pure Theory of Law, University of California Press, Berkeley, 1967.

Kornhauser, L., "Modeling collegial courts I: Path-dependence", en International Review of Law and Economics, Vol. 12, No 2, 1992, pp. 169-185.

Kornhauser, L., "Modeling Collegial Courts II: Legal Doctrine”, en Journal of Law, Economics and Organization, Vol. 8, 2003, p. 441.

Mac-Clure, L., "Tribunal Constitucional y los Derechos: La Discusión Pendiente”, en Sierra L. (ed.), Frente a las Mayorías. Leyes Supramayoritarias y el Tribunal Constitucional en Chile, Centro de Estudios Públicos, Santiago, 2011, pp. 169-275.

Martin, A., Quinn, K. y Epstein L., "The Median Justice on the U.S. Supreme Court”, en North Carolina Law Review, Vol. 83, 2005, pp. 1275-1321. 
Navia, P. y Ríos-Figueroa J., "The Constitutional Adjudication Mosaic of Latin America”, en Comparative Political Studies, Vol. 38, No 2, 2005, pp. 189-217.

Ribera, T., "Función y Composición del Tribunal Constitucional de 1980", en Revista Estudios Públicos, Vol. 27, 1987, pp. 77-112.

Ríos, L., "El Nuevo Tribunal Constitucional”, en Zúñiga F. (ed.), Reforma Constitucional, Lexis Nexis, Santiago, 2005, pp. 627-650.

Rohde, D. y Spaeth H., Supreme Court Decision Making, WH Freeman, San Francisco, 1976.

Rousseau, D., La Justice Constitutionnelle en Europe, Montchrestien, Paris, 1992.

Schneider, M., "Judicial Career Incentives and Court Performance: An Empirical Study of the German Labour Courts of Appeal”, en European Journal of Law E Economics, Vol. 20, 2005, p. 127.

Schubert, G., The judicial Mind: The Attitudes and Ideologies of Supreme Court Justices, 1946-1963, Northwestern University Press, Chicago, 1965.

SCRIBner, D., "The Judicialization of (Separation of Powers) Politics: Lessons from Chile", en Journal of Politics in Latin America, Vol. 2, N³, 2010, pp. 71-97.

Segal, J. y Cover A., "Ideological Values and the Votes of US Supreme Court Justices", en American Political Science Review, Vol. 83, 1989, p. 557.

Segal, J. y Spaeth H., The Supreme Court and the Attitudinal Model Revisited, Cambridge University Press, Cambridge, 2002.

Shapiro, M., Law and Politics in the Supreme Court: New Approaches to Political Jurisprudence. Free Press of Glencoe, New York, 1964.

Silva, E., The State and Capital in Chile: Business Elites, Technocrats, and Market Economics, Westview Press, New York, 1996.

Silva, L., El Control de Constitucionalidad de los Actos Administrativos Legales, Legal Publishing, Santiago, 2009.

Silva, L., “¿Es el Tribunal Constitucional el supremo intérprete de la Constitución?”, en Revista de Derecho de la Universidad Católica de Valparaíso, Vol. 38, 2012, pp. 573-616.

Valenzuela, E., El Tribunal Constitucional de Chile y las Reformas que se analizan en el Congreso Nacional, Tribunal Constitucional No 3, Santiago, 1999.

Verdugo, S., "Aportes del modelo de disidencias judiciales al sistema político: pluralismo judicial y debate democrático", en Revista de derecho de la Universidad Católica del Norte, Vol. 18, $\mathrm{N}^{\circ}$ 2, 2011, pp. 217-272.

Verdugo, S. y Ottone C., "Revisitando el Debate Sobre los Abogados Integrantes y la Independencia del Poder Judicial", en Actualidad Jurídica, Universidad del Desarrollo, Vol. 27, 2012, pp. 199-219.

Wald, P., "A Response to Tiller and Cross", en Columbia Law Review, Columbia Law School, 1999, pp. 235-261.

ZapatA, P., La jurisprudencia del Tribunal Constitucional, Biblioteca Americana Santiago, Valparaíso, 2002. 